\title{
FOTOGRAFIAS DO BASQUETEBOL NA CIDADE DO RIO GRANDE/RS: MEMÓRIAS ESPORTIVAS
}

\author{
Mateus Trevisan França \\ Universidade Federal do Paraná, Curitiba, Paraná, Brasil \\ Wanderley Marchi Júnior \\ Universidade Federal do Paraná, Curitiba, Paraná, Brasil
}

\begin{abstract}
Resumo
Este artigo explora fontes fotográficas sobre o basquetebol na cidade do Rio Grande/RS nas décadas de 1960 e 1970, para fazer uma problematização histórica da representatividade do basquetebol para a memória da cidade. Discutiremos sociologicamente até que ponto elas devem ser tratadas como documentos de memória. Primeiramente apresentaremos brevemente nossa abordagem das fontes fotográficas e um breve histórico da cidade. Após essas apresentações, utilizaremos nosso material imagético para montar uma linha cronológica da modalidade e utilizaremos nosso referencial teórico para discutir nosso objeto por meio dessas fotografias. Por fim, faremos algumas considerações finais sobre a representação do basquetebol local apontada ao longo do trabalho.
\end{abstract}

Palavras-chave: Fotografia. Memória. Basquete.

\section{Introdução}

Iniciando o estudo de fotografias como elementos de análise científica, nossas primeiras expectativas sobre o tema eram em como validar nosso tema por meio do retrato do real: a fotografia. Utilizá-la para comprovar que tudo aconteceu de fato! Porém, logo nos primeiros encontros percebemos rapidamente que nossa visão sobre esse "pequeno pedaço do real" é na verdade um pequeno pedaço de dúvidas sobre o que não estava nela presente, sobre o porquê daquele "cenário", daquele ângulo. Quem eram aquelas pessoas? Quem e por que selecionou aquela foto para expor aos outros?

Perseguindo esse caminho em nossa pesquisa, devemos apresentar nossos objetivos: problematizar o uso de fotografias como retrato da realidade; identificar, em nossas fotografias, elementos pertinentes para a validade para nossa pesquisa; demonstrar construções fotográficas que possam se tornar representações sociais.

Para isso, nos valemos de alguns autores que escreveram sobre esse tema e que apontam direções que em princípio parecem opostas, mas que demonstram a relativa pluralidade nas possibilidades de interpretação do objeto fotográfico. Nesse intento, começaremos explicitando nossa postura frente ao ato fotográfico concordando com o que escreve Barthes (1984, p. 13):

Em primeiro lugar, encontrei o seguinte. O que a Fotografia reproduz ao infinito só ocorreu uma vez: ela repete mecanicamente o que nunca mais poderá repetir-se existencialmente. Nela, o acontecimento jamais se sobrepassa para outra coisa: ela reduz sempre o corpus de que tenho necessidade ao que vejo; ela é o Particular absoluto, a Contingência soberana, fosca e um tanto boba o Tal (tal foto, e não a foto), em suma a Tique, a Ocasião, o Encontro, o Real, em sua expressão infatigável. 
O autor explicita uma compreensão filosófica acerca do fotográfico, que envolve o objeto, a folha de papel com a reação química nela impressa, mas questiona também a configuração necessária para que essa impressão química ocorra. Em termos científicos, ele coloca desde já a nossa frente uma reflexão que nos impede de retornar a um entendimento que reduza o fotográfico à representação daquilo que realmente ocorreu como pensávamos anteriormente.

Dessa maneira, apresentamos nosso objeto, que se enquadra como uma parte da configuração da cidade do Rio Grande ${ }^{1}$ que se apresenta como a cidade mais antiga do estado do Rio Grande do Sul e em termos esportivos, muita tradição nos mais variados esportes. Nosso trabalho tratará do basquetebol pela configuração vitoriosa ${ }^{2}$ da modalidade especialmente ao longo das décadas de 1960 e 1970 do século passado ${ }^{3}$.

Apresentados nossos objetivos, nossa linha de análise dos fotográficos e nosso objeto, trataremos a seguir de aprofundar cada um desses elementos nos capítulos seguintes. E, ao final da discussões faremos algumas considerações das nossas percepções sobre o tema abordado.

\section{Cidade do Rio Grande}

Para entendermos a expansão do basquetebol nos clubes ${ }^{4}$ que iniciaram com a prática do remo e do "futebol de salão" e, posteriormente, foram à prática do basquete, é preciso entender a história da cidade do Rio Grande. A história conta com uma formação de luta e resistência, em detrimento do crescimento industrial, alavancado por grandes indústrias, pela criação da primeira refinaria de petróleo do país e, consequentemente, suas lutas feitas pelos movimentos sindicais e trabalhistas.

Essa tradição de luta e resistência, construída no início da sua história e reafirmada nas lutas desenvolvidas pelos trabalhadores na primeira metade do século XX, até a primeira metade da década de 60, foi interrompida com o golpe militar de 1964 . O golpe perseguiu e baniu os seus opositores e Rio Grande foi transformada em Área de Segurança Nacional. A cidade, bem como o país inteiro, sofreu um processo de "apagamento" de sua memória.

Assim como na esfera política e econômica, na social também foram sentidos os efeitos dessa mudança. Rio Grande, berço do basquetebol no Rio Grande do Sul ${ }^{5}$, cenário das grandes corridas de rua, das provas de remo e natação, dos clubes de futebol, do "futebol de salão", do vôlei e do handebol e suas grandes disputas que lotavam os estádios e os ginásios;

\footnotetext{
${ }^{1}$ A cidade do Rio Grande foi oficialmente fundada em 19 de fevereiro de 1737 pelo Brigadeiro José da Silva Paes. Hoje, com 275 anos tem uma população de 197.228 habitantes e encontra-se 333Km distante da capital do Estado, Porto Alegre. Site IBGE disponível em: <http://www.ibge.gov.br/cidadesat/topwindow.htm?1>. Acesso em: 28 ago. 2013.

${ }^{2}$ Entre os anos de 1967 e 1976, a cidade do Rio Grande foi tricampeã estadual adulta de basquete, primeiramente com o Clube de Regatas Rio Grande (C.R.R.G,1967-1973) e posteriormente com o Ipiranga Atlético Clube (I.A.C, 1976). O Clube de Regatas Rio Grande também sagrou-se campeão do interior do estado do Rio Grande do Sul em 1970, e o Clube Almirante Barroso foi vice-campeão estadual na década de 70 segundo fontes orais.

${ }^{3}$ Algumas informações adicionais sobre a chegada do basquetebol a cidade do Rio Grande e alguns de seus personagens pode ser obtidas em: FRANÇA, M. T. Memórias do Basquetebol na Cidade do Rio Grande (RS). Universidade Federal do Rio Grande, Rio Grande, 2009.

${ }^{4}$ GAUTÉRIO, M. S. A cidade, as águas e as práticas esportivas: a história do Clube Regatas Rio Grande (1897-1999). Trabalho de Conclusão do Curso de História/FURG, 2000. E LEMOS, J. B. As interfaces do basquetebol veterano masculino do Clube Regatas Rio Grande-RS. Trabalho de Conclusão de Curso de Educação Física/URCAMP, 2006.

5 JORNAL RIO GRANDE. Cidade do Rio Grande introdutora do Basket-Ball no Estado. Jornal Rio Grande. Rio Grande-RS, no 176, p.7. 17/07/1962.
} 
dos grandes cinemas e teatros; berço de grandes artistas; terra do clube de futebol ${ }^{6}$ mais antigo do Brasil. Percebemos hoje na população local que existe um esquecimento dessas atividades esportivas e suas emergências pioneiras no estado.

Seguindo no intuito de demarcar histórica e socialmente nosso objeto iniciaremos a apresentação de nossos fotográficos para então apresentarmos as discussões a partir de nosso referencial teórico mais específico sobre o tema.

\title{
As imagens como instrumento para a construção da memória esportiva na Cidade do Rio Grande/RS
}

Concordamos com Bencostta (2011, p. 398-399), quando descreve sua postura frente à utilização fotográfica em pesquisas de cunho histórico, ao dizer:

\begin{abstract}
Além de ser uma interpretação do real, a fotografia é um vestígio diretamente calcado sobre o real, como uma pegada. Partindo desse ponto, ficou claro que os objetivos de nossas indagações deveriam adotar procedimentos de investigação que não se circunscrevessem apenas ao levantamento e organização do material iconográfico, mas a um exercício contínuo de análise e interpretação que procurasse entender essa forma de representação visual e o seu uso em trabalhos históricos [...]
\end{abstract}

Nosso objeto possui uma historicidade que procuraremos problematizar com a ajuda de algumas imagens, sobretudo das décadas de 60 e 70 do século passado, época selecionada como foco principal desse artigo devido a sua efervescência em termos de títulos e histórias relacionadas.

Contudo a primeira foto selecionada é de alguns anos antes devido ao seu conteúdo, gerador do interesse inicial em pesquisar a modalidade e apesar da impossibilidade encontrada em verificar sua validade.



Figura 1: Placa fixada no ginásio do Clube de Regatas Rio Grande em homenagem aos seus sócios introdutores do basquetebol na cidade e no estado. ${ }^{7}$

\footnotetext{
${ }^{6}$ Sport Clube Rio Grande (S.C.R.G). Para mais, ver: RIGO, Luiz Carlos. Memórias de um Futebol de Fronteira. Pelotas: Editora da UFPel, 2004.

${ }^{7}$ Imagem cedida pelo site papareia. Disponível em: <http://www.guaipeca.blogger.com.br/>. Acesso em 22 fev. 2014.
} 
Nosso conhecimento é de que essa placa foi uma homenagem aos atletas e pioneiros da modalidade fixada no ginásio do Clube de Regatas Rio Grande no fim da década de 1950. Porém, podemos questionar, concordando com o que escreve Lowental (1998, p. 134), demonstrando a postura frente à história com a qual trabalhamos: “[...] contar histórias também impõe suas exigências na história. [...] A verdade na história não é a única verdade sobre o passado; cada história é verdadeira em infinitas maneiras, maneiras essas que são mais específicas na história e mais gerais na ficção.”. Nessa perspectiva, o motivo da importância em confirmar o "real começo" do basquetebol na cidade, a ponto de afirmá-lo fixando a placa na parede do ginásio do clube tem uma conotação histórica diferente da que expressamos por meio do autor, ou seja, visa a imprimir esse fato como ícone históricoesportivo na sociedade.

Independentemente disso, como espectador dessa imagem, fui instigado a procurar uma melhor contextualização histórica da modalidade, o que me permitiu eleger as décadas de 1960 e 1970 como momentos de maior efervescência fotográfica, jornalística e da prática. Buscando a validação da foto anterior, encontramos uma manchete em um jornal local que contribui com essa afirmação:

RIO GRANDE 17 DE JULHO DE 1962

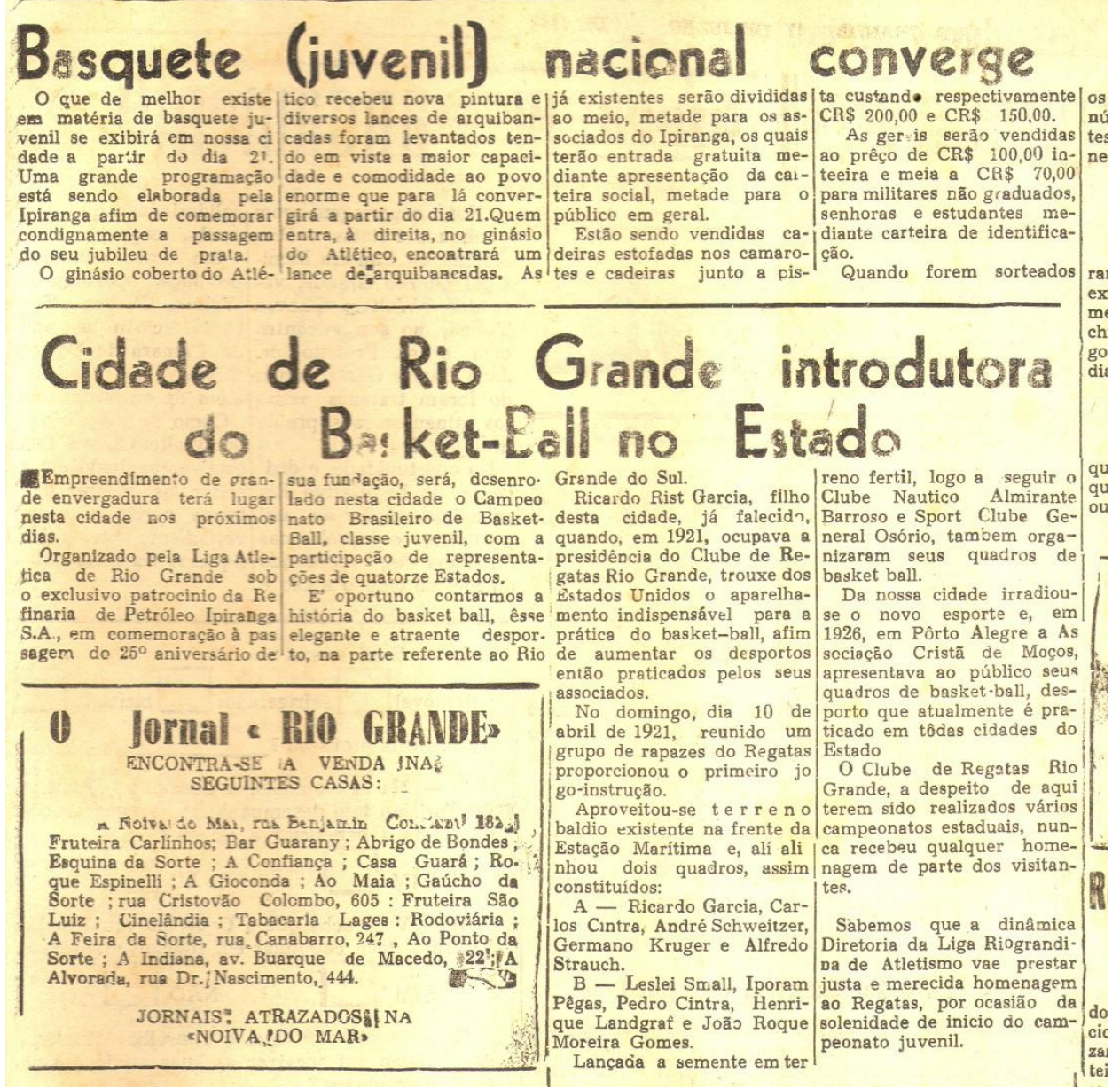

Figura 2: Reportagens Jornal Rio Grande do dia 17 de julho de 1962. Na parte superior da página reportagem sobre o campeonato nacional de seleções categoria juvenil que seria sediado na cidade dali a alguns dias e financiado pela refinaria de petróleo Ipiranga S/A em razão da comemoração do seu aniversário de 25 anos. A segunda reportagem diz respeito a uma homenagem ao pioneirismo do basquetebol na cidade e aos introdutores da modalidade no estado do Rio Grande do Sul. 
Percebemos com o auxílio dessa reportagem um vestígio de credibilidade nas informações referente à placa. Contudo, mais importante do que a validação são as informações sobre o desenvolvimento da cidade nas décadas posteriores ao fato ratificado referentes à reportagem na parte superior do recorte. Em termos sociais, a refinaria Ipiranga $\mathrm{S} / \mathrm{A}^{8}$ representou, juntamente com as grandes indústrias e o pólo naval, um grande avanço econômico para a cidade e em termos de basquetebol a organização e patrocínio de um evento nacional da modalidade pode significar a vontade de afirmar a modalidade para os habitantes ou pode suprir anseios de pessoas já familiarizadas com ela.

Dessa maneira, Souza (2001, p. 78) descreve esse apoio ou a maneira como esse vestígio identifica a importância no olhar do pesquisador para algumas dimensões das fotografias:

[...] é preciso atentar para as múltiplas faces e realidades da imagem fotográficas como nos adverte KOSSOY (1998). Esse autor chama a atenção para as dimensões da fotografia como memória e representação, fruto de uma elaboração cultural, estética e técnica. Para ele, a compreensão da imagem passa pela desmontagem do processo de construção da representação, o que significa considerar também os usos ou aplicações que teve a imagem [...]

A autora descreve dimensões que tentaremos utilizar nas imagens seguintes, em que as fotografias terão maiores apelos estéticos e técnicos. Porém, no caso anterior ficam evidentes em ambas as reportagens, a tentativa de elaboração cultural das manchetes e um processo de representação do basquetebol historicamente e na atualidade através de seu novo apelo, o basquetebol moderno, patrocinado.

$\mathrm{Na}$ tentativa de traçarmos uma linha cronológica da modalidade, apresentamos a seguir uma fotografia de uma equipe juvenil do Clube de Regatas Rio Grande, clube anunciado como o pioneiro do basquetebol no estado do Rio Grande do Sul, tanto pela figura 1 como pela figura 2 , essa foto apresenta um elemento de continuidade histórica da modalidade entre os clubes da cidade e possibilita uma primeira análise da tônica.

${ }^{8}$ TORRES, L. H. Cronologia básica da história da cidade do Rio Grande (1737-1947). Biblos, v. 22, n. 2, 2008. p. 9-18. 


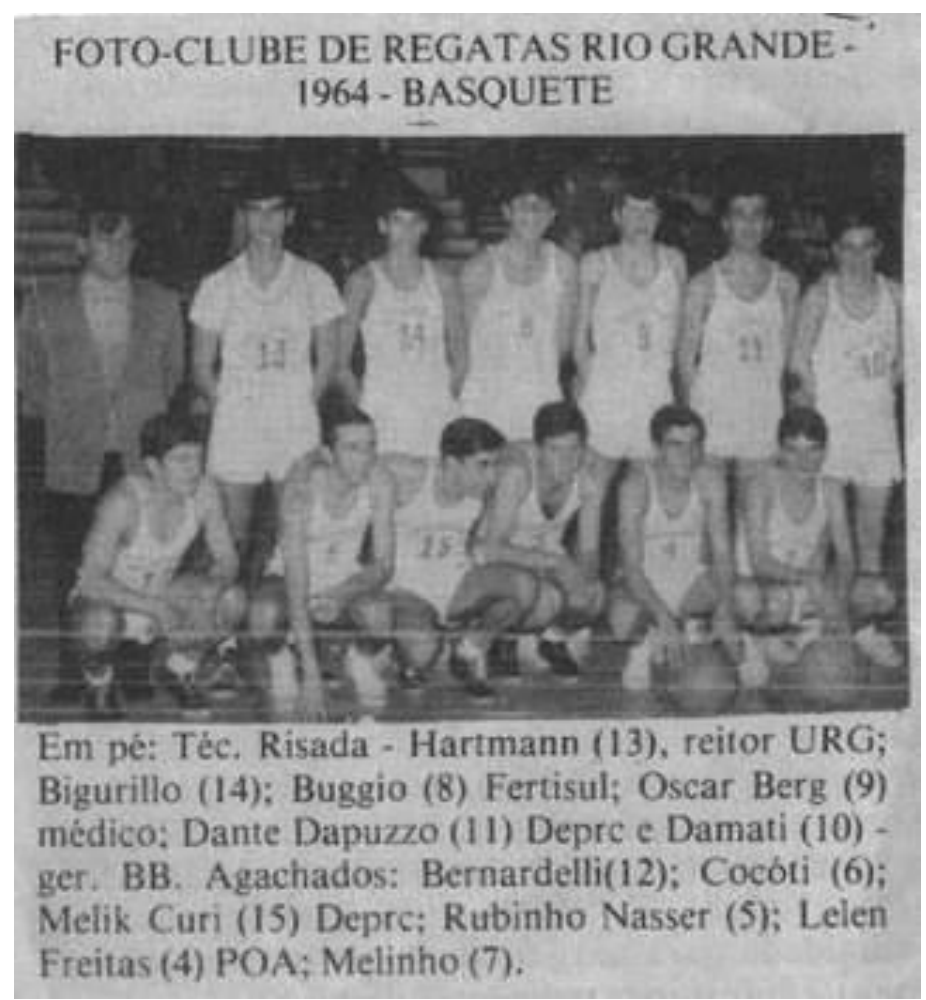

Figura 3: Foto de jornal no ano de 1964 da equipe juvenil do Clube de Regatas Rio Grande ${ }^{9}$

A imagem revela a equipe juvenil do Clube de Regatas Rio Grande do ano de 1964, disputando uma partida no ginásio do Ipiranga Atlético Clube. Mais do que informações sobre o fato em si, a imagem revela informações sobre o tipo de fotografias que foram mantidas a respeito desse fato pensando na publicação em um periódico. Dessa maneira, podemos problematizar o uso social dessa imagem utilizando Bourdieu (2003, p. 135) quando descreve:

Seria muito fácil mostrar que esta representação social contém a falsa evidência dos preconceitos. Na verdade, a fotografia fixa um aspecto da realidade que nunca é o resultado de uma relação arbitrária e, como resultado, uma transcrição: entre todas as qualidades do objeto somente são mantidas aquelas visuais que ocorrem no momento e de um ponto de vista único; estas são transcritas em preto e branco, geralmente pequenas e sempre projetadas no plano. Em outras palavras, a fotografia é um sistema convencional que exprime o espaço de acordo com as leis da perspectiva (deveria dizer: de uma perspectiva) $[\ldots]^{10}$ (tradução nossa).

O autor nos aponta um uso da fotografia que corresponde a aspectos sociais diretamente vinculados ao esporte e a interesses de periódicos na publicação dessas imagens. Problematiza também a maneira como ficarão lembrados, os indivíduos, o clube e as marcas associadas a essa imagem.

Contudo, juntamente aos interesses e influências sofridos pelos clubes e atletas de basquete que aparecem nessas fotografias, os grupos assumem algumas características e peculiaridades que lhes eram atribuídas por meio dessas imagens e posturas concretizadas nelas.

A próxima fotografia nos fornece uma ideia dos caminhos percorridos pelos clubes e pela fotografia em uma via de mão dupla, ou como fazem referência Elias e Dunning (1992), com um aspecto mimético. Ambos se influenciaram mutuamente, as imagens vinculadas ou

\footnotetext{
${ }^{9}$ Imagem cedida pelo site papareia. Disponível em: <http://www.guaipeca.blogger.com.br/>. Acesso em 22 fev. 2014.
} 
não aos jornais e periódicos, levando os indivíduos ao conhecimento da população da cidade com aspecto vitorioso, heroico e os grupos de atletas desenvolvendo suas habilidades e vencendo jogos e torneios como as fotografias a seguir mostravam.

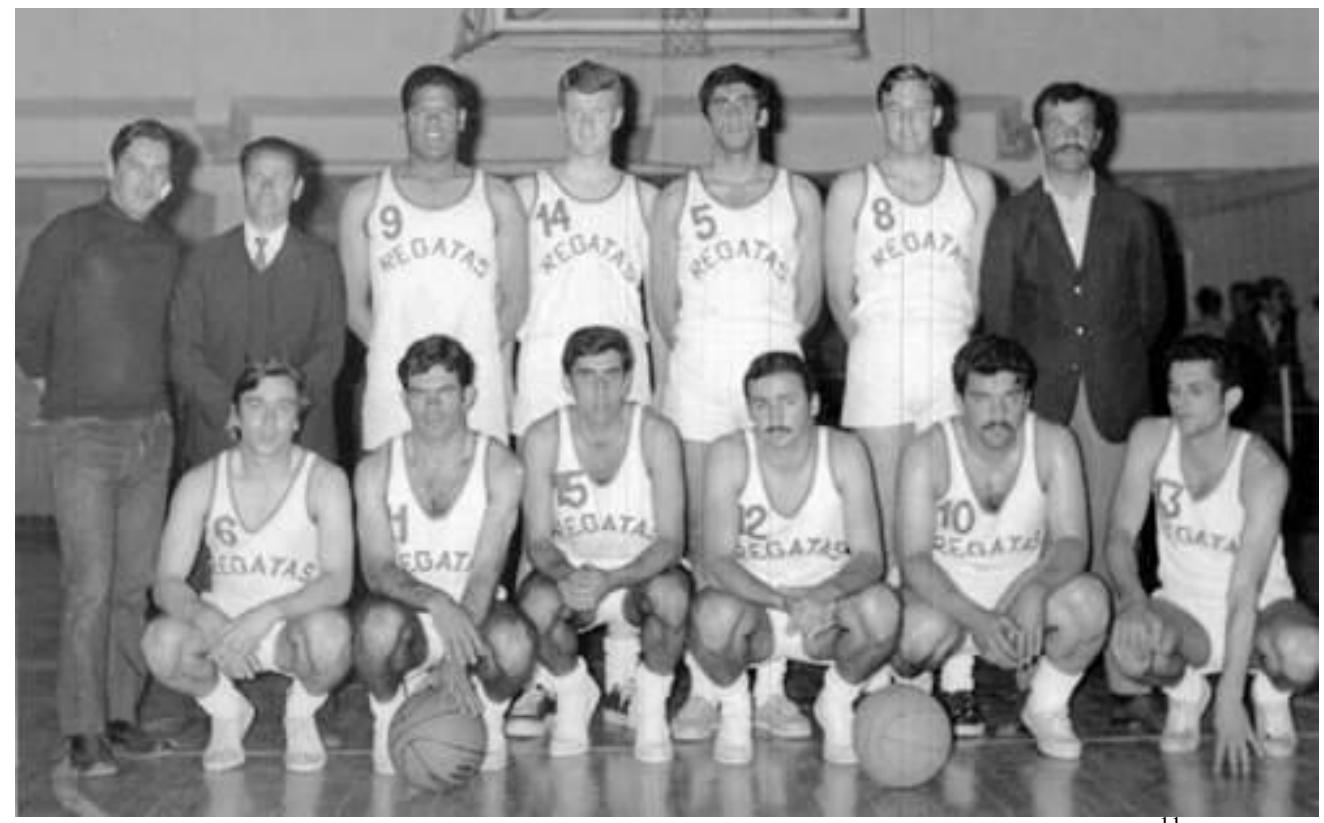

Figura 4: Equipe do Clube de Regatas Rio Grande do fim dos anos $1960^{11}$



Figura 5: Equipe do Clube de Regatas Rio Grande campeã estadual em $1967^{12}$

\footnotetext{
${ }^{10}$ Sería demasiado fácil mostrar que esta representación social encierra la falsa evidencia de los prejuicios. De hecho, la fotografía fija un aspecto de lo real que nunca es el resultado de una relación arbitraria y, por ello mismo, de una transcripción: entre todas las cualidades del objeto, sólo son retenidas aquellas visuales que se dan en el momento y a partir de un punto de vista único; éstas son transcritas en blanco y negro, generalmente reducidas y siempre proyectadas en el plano. Dicho en otras palabras, la fotografía es un sistema convencional que expresa el espacio de acuerdo con las leyes de la perspectiva (habría que decir: de una perspectiva) [...]

${ }^{11}$ Imagem cedida pelo site papareia. Disponível em: <http://www.guaipeca.blogger.com.br/>. Acesso em $22 \mathrm{fev}$. 2014.

${ }^{12}$ Imagem cedida pelo site papareia. Disponível em: <http://www.guaipeca.blogger.com.br/>. Acesso em: 22
} 


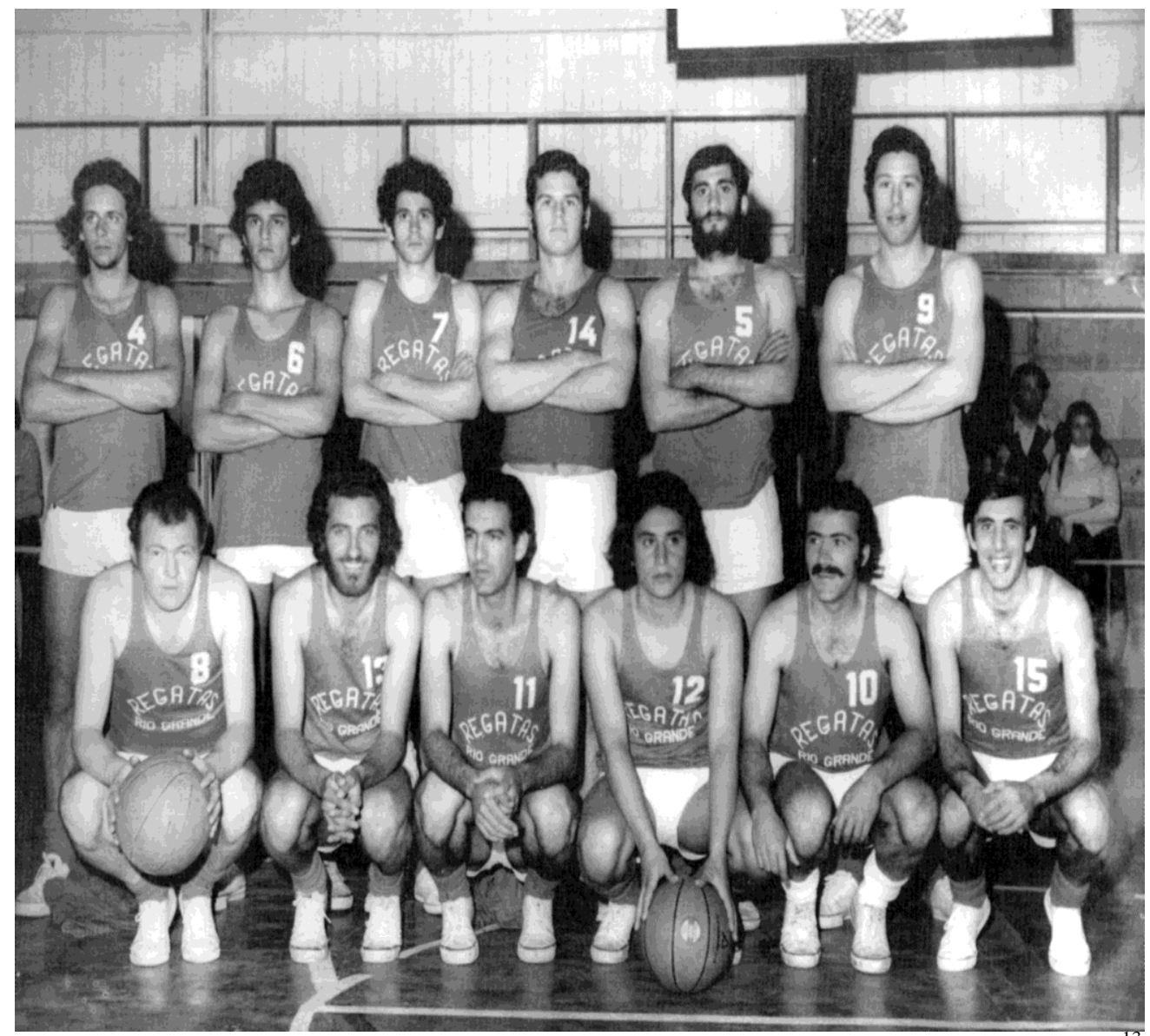

Figura 6: Equipe do Clube de Regatas Rio Grande campeão estadual adulto no ano de $1973^{13}$

A primeira imagem representa a equipe adulta do Clube de Regatas Rio Grande no início dos anos 1960 antes da conquista do primeiro título estadual. As outras duas imagens foram tiradas e veiculadas como fotografias da equipe campeã estadual adulta de basquetebol, percebemos o elemento de repetição estética, as poses muito semelhantes embora os ângulos sejam diferentes, outra diferença é que na primeira imagem podemos perceber a importância dada aos torcedores que fazem parte da composição da fotografia, com um destaque maior até do os jogadores que se encontram no primeiro plano da imagem e percebemos mais detalhes do local onde a fotografia foi feita, no ginásio do Clube de Regatas Rio Grande, dentro da quadra de jogo. Outro elemento da fotografia que nos chama a atenção são pessoas, no primeiro plano que não são atletas e que se apresentam ao lado deles. Bourdieu (2003, p. 143144) descreve alguns elementos sociais pretendidos pela fotografia de grupos e em situações solenes:

Na maior parte das fotografias de grupo, os sujeitos se apresentam apertados uns aos outros (sempre no centro da imagem) e muitas vezes abraçados. Os olhos convergem em direção ao alvo, para que toda a imagem indique que o seu centro ausente. Quando se trata de uma parelha, os indivíduos são capturados em torno da cintura em uma pose completamente convencional. As regras de conduta que devem ser tomadas frente a objetiva, por vezes, surgem à consciência, sob a forma positiva ou negativa: repreende aquele a quem, em um grupo se reuniu para uma ocasião solene como um casamento, por exemplo, adota uma atitude inconveniente ou omite

fev. 2014.

${ }^{13}$ Imagem cedida pelo site papareia. Disponível em: <http://www.guaipeca.blogger.com.br/>. Acesso em: 22 fev. 2014. 
olhar para a objetiva e posar. Como dizem, "está ausente." A convergência, os olhares e a diposição das pessoas objetivamente atesta a coesão do grupo. ${ }^{14}$ (tradução nossa)

Percebemos por meio do excerto alguns elementos de análise que nos ajudam minimamente a notar com que tipo de grupo estamos lidando, mais ou menos coeso, mais ou menos ligado a hierarquias institucionais. Mas também questionamos essa observação feita pelo autor quanto à convergência dos olhares corresponder ao grau de coesão dos grupos, já que certamente mais de uma câmera pudesse estar presente no momento das fotografias dividindo a atenção dos olhares.

Já a segunda imagem apresenta menos elementos exteriores ao grupo fotografado, porém emergem da imagem outros tipos de relações sociais, conforme descreve Bourdieu (2003, p. 146-147):

A convenção que se assume para uma fotografia se refere, aparentemente, ao estilo de relações sociais favorecidas por uma sociedade enquanto hierarquizada e estática [...] em uma sociedade onde os intercâmbios, estritamente estabelecidos pelas convenções institucionalizadas, são produzidos sob a obsessão com o julgamento dos outros, sob a pressão da opinião - pronta para condenar em nome de regras indiscutíveis e incontestáveis - e eles estão sempre dominados pela preocupação de dar de si a melhor imagem, a mais coerente com o ideal de dignidade e honra. Como, nessas condições, a representação da sociedade poderia ser outra coisa senão a representação da sociedade em representação ${ }^{15}$ (tradução nossa)

Os usos feitos das imagens das vitórias do basquete riograndino carregam a preocupação do que o autor ressalta como a vontade de mostrar o melhor, o mais honorável. Esse destaque aos pontos positivos, ou o que se crê como positividade na vitória, por vezes não se transmite com imagens como as anteriores. Contudo, a seguir apresentamos duas reportagens que contam a história da conquista do primeiro campeonato estadual pelo Clube de Regatas (1967), uma imagem de continuidade cronológica do basquetebol local e da proporção atingida pela modalidade na América do Sul.

\footnotetext{
${ }^{14}$ En la mayor parte de las fotografías de grupo, los sujetos se presentan apretados unos junto a los otros (siempre en el centro de la imagen) y, a menudo, abrazados. Las miradas convergen hacia el objetivo de modo que toda la imagen indica lo que es su centro ausente. Cuando se trata de una pareja, los sujetos se cogen por la cintura en una pose completamente convencional. Las normas de la conducta que debe tenerse frente al objetivo a veces afloran a la conciencia, bajo la forma positiva o negativa: se reprende a aquel que, en un grupo reunido para una ocasión solemne, como una boda por ejemplo, adopta una actitud inconveniente u omite mirar al objetivo y posar. Como suele decirse, "está ausente". La convergencia las miradas y la diposición de las personas atestigua objetivamente la cohesión del grupo.

${ }^{15} \mathrm{El}$ convencionalismo que se asume para una fotografía remite, al parecer, al estilo de relaciones sociales favorecidas por uma sociedad a la vez jerarquizadas e estática [...] en una sociedad donde los intercambios, estrictamente establecidos por convenciones institucionalizadas, se producen bajo la obsesión por el juicio de los otros, bajo la presión de la opinión - pronta a condenar en nombre de normas indiscutibles e indiscutidas -, y están siempre dominados por la preocupación de dar de sí la mejor imagen, la más conforme con el ideal de dignidad y de honor. ¿Cómo, en esas condiciones, la representación de la sociedad podría ser otra cosa que la representación de la sociedad en representación?
} 


\section{HÁ 30 ANOS EM ZH}

As notícias abaixo foram publicadas na edição de 16 de dezembro de 1967:

\section{Campeão do basquete} sai hoje

Inter foi o primeiro dos grandes a cair no basquete. Não resistiu ao maior entusiasmo e ao maior ímpeto da equipe do Clube Regatas e perdeu de 51 a 45 . A pequena diferença no marcador revela bem o equilíbrio da partida e o bom espetáculo que os dois clubes ofereceram ao público. Com esse resultado, o Regatas foi para a final e decide hoje o título do estadual de basquete contra o Cruzeiro.

Como ficou - O Clube Regatas, de Rio Grande, conquistou o título do estadual de basquete num jogo bastante tumultuado e disputado. A partida só acabou às $3 h$ da madrugada, porque a torcida rio-grandina invadiu a quadra diversas vezes. $O$ Cruzeiro foi derrotado por 52 a 51 .

Figura 7: Reportagem da Zero Hora de 16 de dezembro de 1997 fazendo referência à reportagem impressa em sua edição de 30 anos antes sobre a vitória do campeonato estadual pelo Clube de Regatas Rio Grande. ${ }^{16}$

\footnotetext{
${ }^{16}$ Imagem cedida pelo site papareia. Disponível em: <http://www.guaipeca.blogger.com.br/>. Acesso em: 22 fev. 2014.
} 


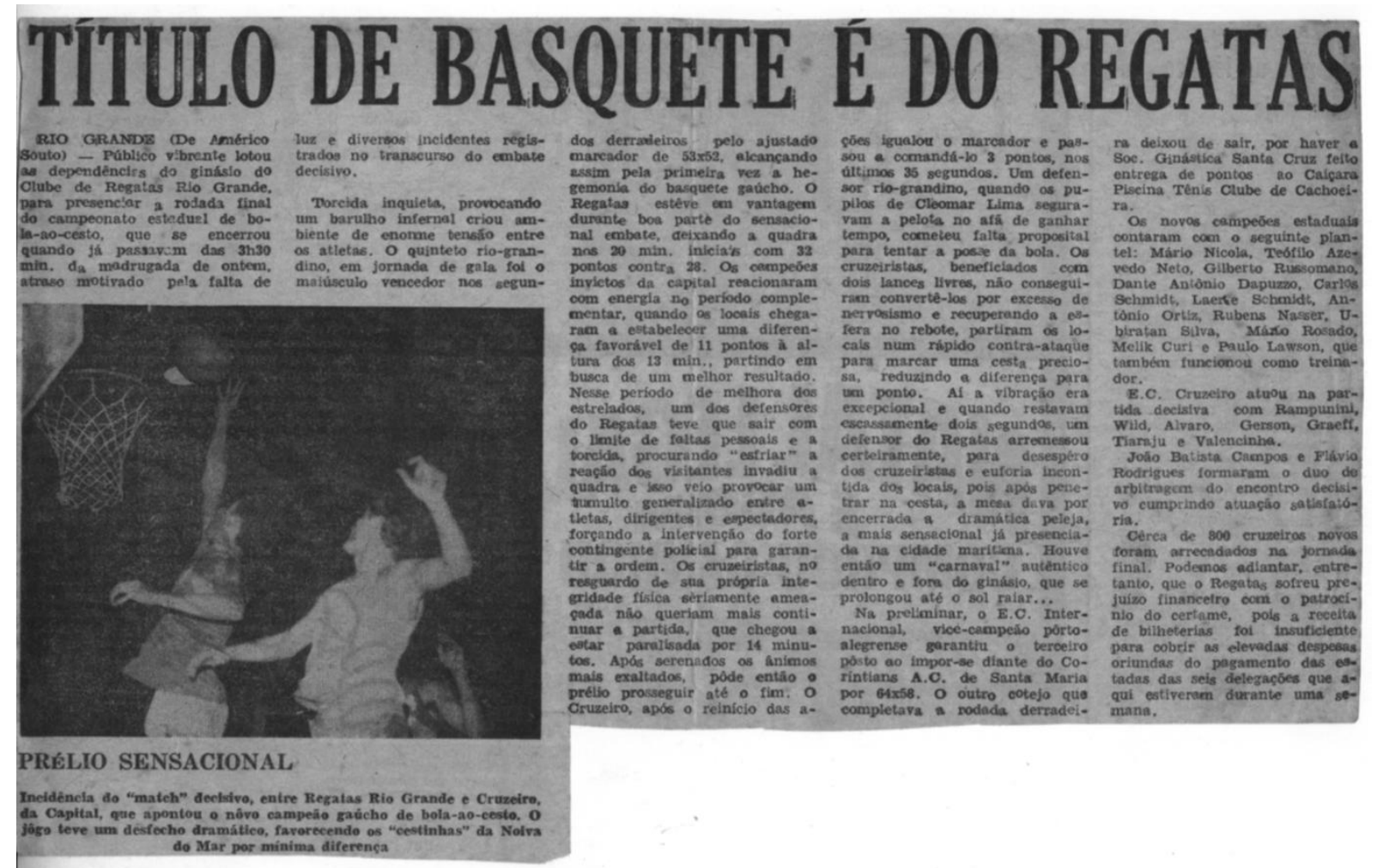

Figura 8: Reportagem de jornal do dia posterior à conquista do primeiro campeonato estadual adulto do Clube de Regatas Rio Grande em $1967 .^{17}$

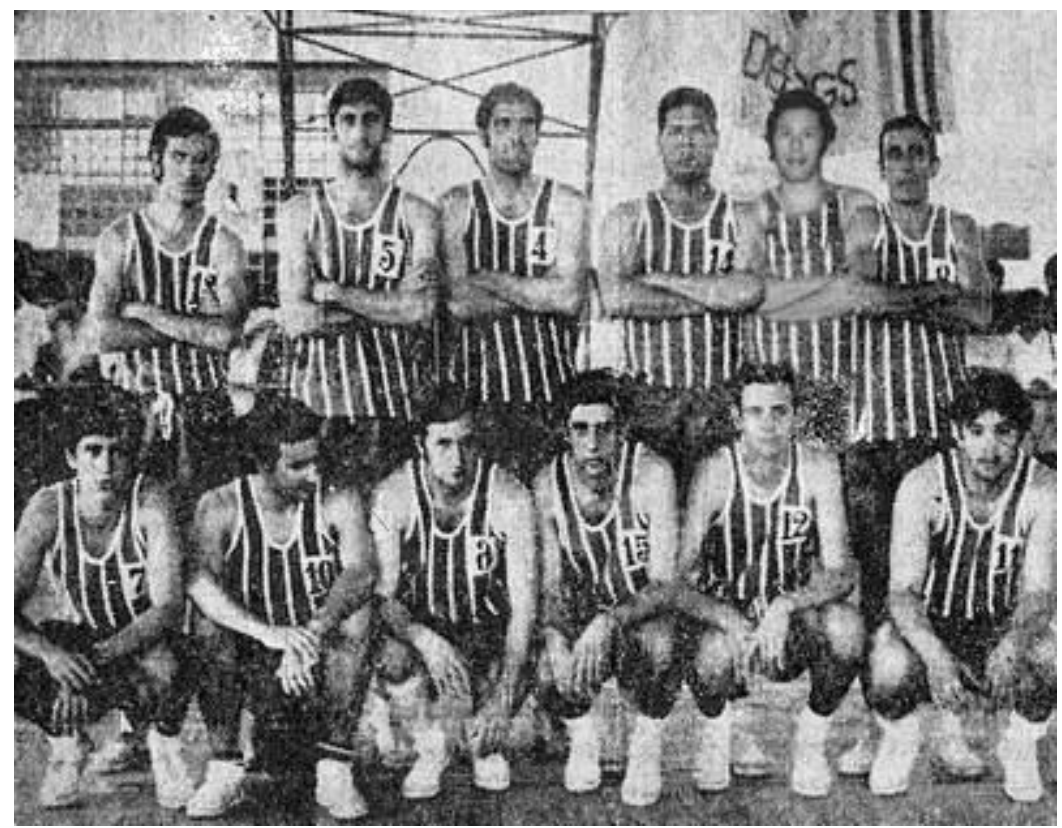

Figura 9: Equipe do Clube de Regatas Rio Grande campeã do interior do estado em $1970^{18}$

\footnotetext{
${ }^{17}$ Imagem cedida pelo site papareia. Disponível em: <http://www.guaipeca.blogger.com.br/>. Acesso em: 22 fev. 2014.

${ }^{18}$ Imagem cedida pelo site papareia. Disponível em: <http://www.guaipeca.blogger.com.br/〉. Acesso em: 22 fev.2014.
} 


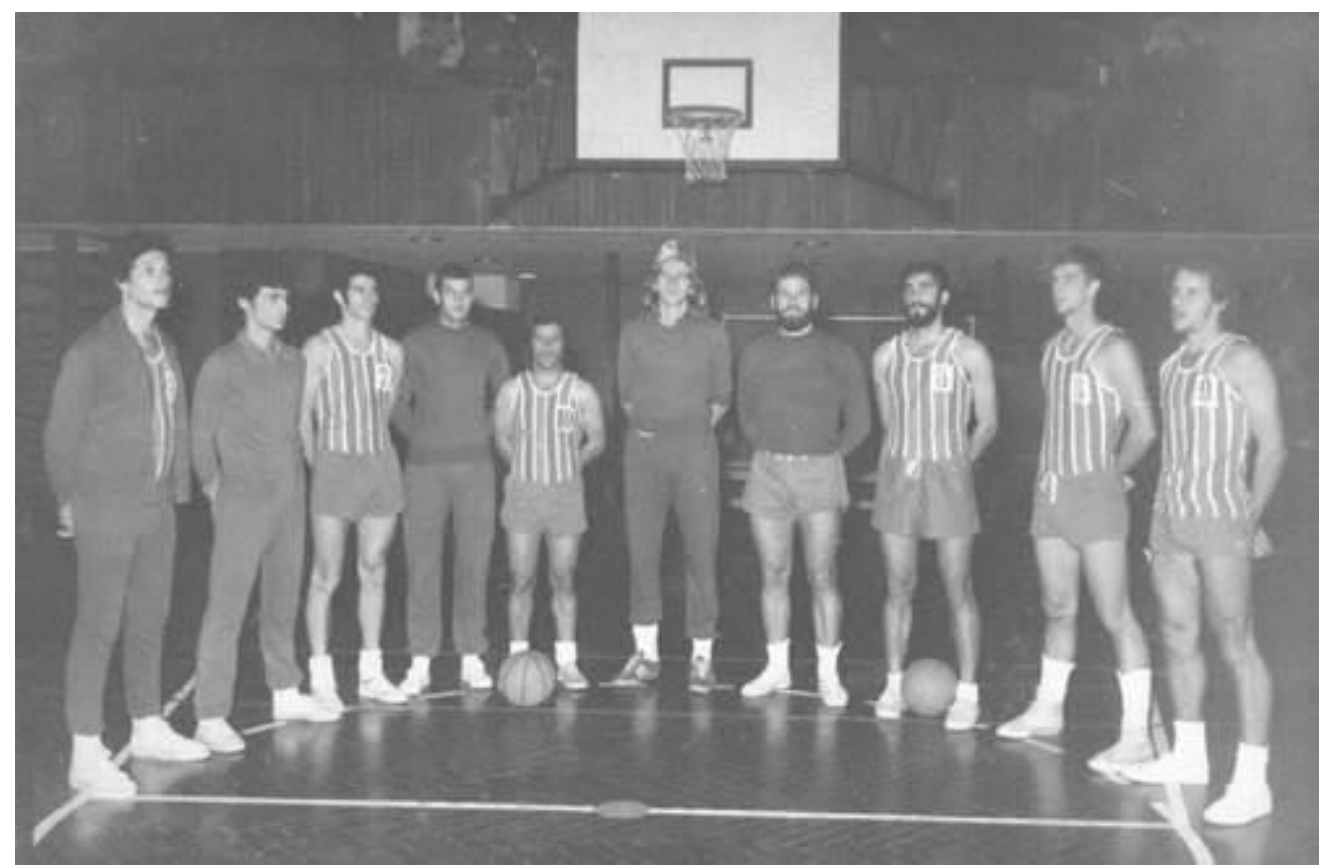

Figura 10: Foto da equipe do Clube de Regatas Rio Grande junto à seleção uruguaia em visita a cidade do Rio Grande para jogos amistosos na cidade ${ }^{19}$

As reportagens acima ajudam a compreender, em parte, a situação em que ocorreu a primeira conquista do título estadual adulto pelo Clube de Regatas Rio Grande. A primeira reportagem trata-se de uma reedição da manchete da época da conquista e revela o tumulto causado durante o jogo pela torcida e que culmina na vitória dos riograndinos. A segunda, com maior pompa e rebusque na escrita, conta mais romanticamente a maneira como se deu a conquista, porém sem deixar de lado alguns dados sobre os tumultos que ocorreram durante o jogo.

Seguindo nossa cronologia do basquetebol riograndino, as fotos seguintes mostram a continuação temporal da modalidade, a primeira mostra a representação da equipe do Clube de Regatas Rio Grande no início dos anos 1970 após a conquista do campeonato estadual do interior do estado do Rio Grande do Sul e a segunda representa um encontro entre Brasil e Uruguai também no começo dos anos 1970 para jogos amistosos na cidade do Rio Grande.

As representações dessas imagens fazem referência à maneira pela qual o basquetebol riograndino pretende ser lembrado, ou seja, faz parte da memória do basquetebol riograndino e de como os indivíduos nelas presentes se reconhecem enquanto pertencentes a estes momentos, já que é por meio da memória que somos capazes de destruir a relação dicotômica entre, ação e imaginação, corpo e mente. Através do ato de rememorar criamos, unificamos sentimentos (correlações de momentos passados) e ações presentes, dando vida à imaginação e um novo significado para aquela imagem/sensação do passado (HALBWACHS, 2006).

\section{Considerações finais}

Nosso intuito ao mostrar essas representações imagéticas do basquetebol riograndino foi aproximarmos de um debate sociológico dessas fotografias e evocar, imageticamente, memórias desse basquetebol que teve grande destaque para a sociedade local.

Podemos assim definir essas imagens, como uma memória coletiva desse período histórico que, por estar presente sem "estar presente" possui múltiplas utilizações e múltiplas

\footnotetext{
${ }^{19}$ Imagem cedida pelo site papareia. Disponível em: <http://www.guaipeca.blogger.com.br/〉. Acesso em: 22 fev. 2014.
} 
formas de se manifestar tanto coletiva, quanto individualmente (HALBWACHS, 2006.). Halbwachs (2006, p. 32) demonstra que:

Não basta que eu tenha assistido ou participado de uma cena em que havia outros espectadores ou atores para que, mais tarde, quando estes a evocarem à minha frente, quando reconstituírem cada pedaço de sua imagem em meu espírito, esta composição artificial subitamente se anime e assuma figura de coisa viva, e a imagem se transforme em lembrança. É comum que imagens desse tipo, impostas pelo meio em que vivemos, modifiquem a impressão que guardamos de um fato antigo, de uma pessoa outrora conhecida.

Lembramos que temos certa dualidade intrínseca à utilização fotográfica em um trabalho acadêmico e que de certa forma nos valemos para elencar essas fotografias e não outras, como dito por Le Goff (2013), ora utilizamos as fotografias como documentos, no sentido de uma comprovação histórica dos fatos, ora como monumentos, como instrumento do fazer lembrar aquilo e não outra coisa a respeito de nosso tema.

Nesse jogo de negociação entre, memórias, histórias, fotografias e verdades, compreendemos que essa configuração complexa nos deixa à mercê da impossibilidade de afirmações e convicções sobre quaisquer desses temas concordando com o que explicita Rouillé (2009, p. 67) sobre o tema:

\begin{abstract}
Ora, contrariamente ao que se pode experimentar com a prática fotográfica a mais banal, a verdade, aliás, como a realidade, jamais se desvenda diretamente, através de simples registro. A verdade está sempre em segundo plano, indireta, enredada como um segredo. Não se comprova e tampouco se registra. Não é colhida à superfície das coisas e dos fenômenos. Ela se estabelece. Aliás, é a função dos historiadores, dos policiais, dos juízes, dos cientistas, ou dos fotógrafos estabelecer, conforme procedimentos sempre específicos, a versão da verdade e atualizá-la em objetos dotados de formas. Daí resultam a verossimilhança e a probabilidade, mais do que a verdade. A verdade dos fatos e das coisas não coincide com a verossimilhança dos discursos e das imagens. Apesar de seu contato com as coisas, a fotografiadocumento não foge a regra: ela própria obedece a lógica da verossimilhança, não a da verdade; a passagem da verossimilhança para o real e para o verdadeiro é, também com ela, sempre sinuosa e improvável.
\end{abstract}

Nossa negociação tanto na discussão das imagens propostas (elegidas), quanto nos assuntos de memória e história, não buscam a fixação do real sobre o basquetebol riograndino. Apresentamos e discutimos elementos mnêmicos, históricos, estéticos, sociais oriundos das fotografias entendendo que o assunto não se esgota nas nossas possibilidades de discussão, mas sim, iniciam nelas.

Podemos pensar também na interferência histórica relacionada à memória coletiva, no que diz respeito aos grupos com relações mais imbricadas entre seus membros, como a equipe de basquete que apresentamos, fato que interfere diretamente tanto em atitudes momentâneas como na rememoração coletiva de fatos aceitos ou não dentro do grupo. Halbwachs (2002) faz referência à importância da repetição para a manutenção da tradição de grupos e que pressionam a disputa pela memória dentro das sociedades e seus subgrupos ainda na atualidade:

Não é suficiente colocar um novo material em atos anteriores, constituem os quadros desta vida social, os quadros desaparecem quando as pessoas ou as famílias são banidas e é necessário para reconstruir outras, da mesma maneira, seguindo as mesmas linhas, mas que não terão exatamente a mesma forma nem o mesmo 
aspecto. (p. 164) (Tradução nossa) ${ }^{20}$.

Apesar de pessoas terem interesses em comum, muitas vezes a memória de outros atores ou espectadores de um fato ou cena demonstra no ato de rememorar, outros enfoques, interesses, aspectos que são importantes registros de fatos vivenciados, em dado momento histórico, por aquele coletivo de pessoas.

Nesse artigo não estamos contrapondo ou convergindo versões diferentes de memórias coletivas, mas apresentando uma possibilidade de representação do basquetebol riograndino, que segundo Pollak (1989, p. 4): "[...] não se trata mais de lidar com os fatos sociais como coisas, mas de analisar como os fatos sociais se tornam coisas, como e por quem eles são solidificados e dotados de duração e estabilidade.". Ou seja, não objetivamos um fato social, apenas procuramos compreendê-lo e discuti-lo por meio das imagens.

\title{
BASKETBALL PHOTOS IN RIO GRANDE/RS: SPORT MEMORIES
}

\begin{abstract}
This article will explore photographic sources about basketball in Rio Grande/RS in the 1960s and 1970s, to make a historical questioning of Basketball importance for the memory of the city. We intend to discuss sociologically to what extent they should be treated as memory documents. First, briefly present our approach of photographic sources and do a brief history of the city. After these presentations we will use our imagery equipment to assemble a timeline mode and will use our theoretical framework to discuss our object through these photographs. Finally we will make some considerations remarks on the representation of the local basketball pointed throughout the work.
\end{abstract}

Keywords: Photography. Memory. Basketball.

\section{FOTOGRAFÍAS DEL BALONCESTO EN LA CIUDAD DEL RÍO GRANDE/RS: MEMORIAS DEL DEPORTIVAS}

\section{Resumen}

Este artículo explora fuentes fotográficas sobre el baloncesto en la ciudad de Río Grande/RS en las décadas de 1960 y 1970, para hacer un cuestionamiento histórico de la importancia del baloncesto para la memoria de la ciudad. Discutiremos sociológicamente hasta que punto ellas deben ser tratados como documentos de memoria. En primer lugar presentaremos brevemente nuestro abordaje de las fuentes fotográficas y un breve histórico de la ciudad. Después de estas presentaciones utilizaremos nuestro equipo de imágenes para montar una línea cronológica de la modalidad y va a utilizar nuestro marco teórico para discutir nuestro objeto a través de estas fotografías. Por último, vamos a hacer algunas observaciones finales sobre la representación del baloncesto local, señalado a lo largo del trabajo.

Palabras clave: Fotografía. Memoria. Baloncesto.

\footnotetext{
${ }^{20}$ Il ne suffit pas de mettre une nouvelle matière dans d'anciens actes, constituent les cadres de cette vie sociale, les cadres disparaissent quand les personnes ou les famille s'évanouissent, et il faut en reconstruire d'autres, de la même manière, souivant les mêmes lignes, mais qui n'auront pas exactement la même forme, ni le même aspect.
} 


\section{Referências}

BENCOSTTA, M. L. Memória e Cultura Escolar: a imagem fotográfica no estudo da escola primária de Curitiba. História-SP, v. 30, n. 1, 2011. p. 397-411.

BOLTANSKI, L. La retórica de la figura. In BOURDIEU, P.Um arte medio:ensayo sobre los usos sociales de la fotografía. Barcelona: Editorial Gustavo Gili, SA. 2003. p. 207-234.

BOURDIEU, P. La definición social de la fotografía. In. BOURDIEU, P.Um arte medio:ensayo sobre los usos sociales de la fotografía. Barcelona: Editorial Gustavo Gili, SA. 2003. p. 135-139.

ELIAS, N.; DUNNING, E. A busca da excitação. Coleção Memória e Sociedade. Editora DIFEL, 1992.

FRANÇA, M. T. Memórias do basquetebol na cidade do Rio Grande (RS). Universidade Federal do Rio Grande, Rio Grande, 2009.

GAUTÉRIO, M. S. A cidade, as águas e as práticas esportivas: a história do Clube Regatas Rio Grande (1897-1999). Trabalho de Conclusão do Curso de História/FURG, 2000 .

HALBWACHS, M. A memória coletiva. São Paulo: Centauro, 2006.

HALBWACHS, M. Les Cadres Sociaux de la Memoire. 1. ed. Québec: l'Université du Québec à Chicoutimi - CA, 2002. Disponível em: <http://classiques.uqac.ca//classiques/Halbwachs_maurice/cadres_soc_memoire/cadres_socia ux_memoire.pdf>. Acesso em: 9 jan. 2014.

INSTITUTO BRASILEIRO DE GEOGRAFIA E ESTATÍSTICA (IBGE). Disponível em: <http://www.ibge.gov.br/cidadesat/topwindow.htm?1>. Acesso em: 28 ago. 2013.

JORNAL RIO GRANDE. Cidade do Rio Grande introdutora do Basket-Ball no Estado. Jornal Rio Grande. Rio Grande-RS, nº 176, p.7. 17/07/1962.

LEMOS, J. B. As interfaces do basquetebol veterano masculino do Clube Regatas Rio Grande-RS. Trabalho de Conclusão de Curso de Educação Física/URCAMP, 2006.

LOWENTAL, D. Como conhecemos o passado. Projeto História - SP, n. 17, 1998. p. 63201.

PAPAREIA. Blog de fotografias da cidade do Rio Grande. Disponível em: <http://www.guaipeca.blogger.com.br/>. Acesso em: 22 fev. 2014.

POLLAK, M. Memória, esquecimento, silêncio. Estudos históricos - RJ, v. 2, n. 3, 1989. p. $3-15$.

RIGO, Luiz Carlos. Memórias de um Futebol de Fronteira. Pelotas: Editora da UFPel, 2004. 
ROUILLÉ, A. A fotografia: entre documento e arte. São Paulo: Editora Senac, 2009. p. 6195.

StaREPRAVO, F. A. e NUNES, R. S. Surgimento do Esporte Moderno e do Processo Civilizador. (Mimeo).

TORRES, L. H. Cronologia básica da história da cidade do Rio Grande (1737-1947). Biblos, v. 22, n. 2, p. 9-18, 2008.

Recebido em: 23/01/2015

Revisado em: 31/08/2015

Aprovado em: 01/09/2015

Endereço para correspondência:

franca.mateus52@gmail.com

Mateus Trevisan França

Universidade Federal do Paraná, Setor de Ciências Biológicas, Departamento de Educação Física.

Rua Coração de Maria, BR 116, Km 95, nº 92

Jardim Botânico

80215370 - Curitiba, PR - Brasil 